\title{
$\checkmark$ Research Square \\ Synthesis of Polymer-based ZnO/TiO2 NCs Flexible Sheets as High Dielectric Materials
}

\section{N. Kanwal}

Government College University Faisalabad

\section{S. Pervaiz}

Government College University Faisalabad

\section{A. Rasheed}

Government College University Faisalabad

\section{Saleem}

Lahore University of Management Sciences

ljaz Ahmad Khan ( $\square$ ijazahmad@gcuf.edu.pk)

Government College University Faisalabad https://orcid.org/0000-0002-3554-592X

\section{Research Article}

Keywords: Nanocomposite, Polymer, Conductivity, Impedance, Permittivity, Modulus

Posted Date: June 30th, 2021

DOl: https://doi.org/10.21203/rs.3.rs-666085/v1

License: (c) (1) This work is licensed under a Creative Commons Attribution 4.0 International License. Read Full License 


\title{
Synthesis of polymer-based $\mathrm{ZnO} / \mathrm{TiO}_{2} \mathrm{NCs}$ flexible sheets as high dielectric materials
}

\author{
N. Kanwal ${ }^{\mathrm{a}}$, S. Pervaiz ${ }^{\mathrm{a}}$, A. Rasheed ${ }^{\mathrm{a}}$, M. Saleem ${ }^{\mathrm{b}}$, I. A. Khan ${ }^{\mathrm{a}}$ \\ aPlasma processing of materials and applications, Department of Physics, Government College \\ University Faisalabad, 38000, Faisalabad, Pakistan \\ ${ }^{\mathrm{b}}$ Department of Physics, Lahore University of Management Sciences, Lahore 54000, Pakistan
}

\begin{abstract}
Polymer-based $\mathrm{ZnO} / \mathrm{TiO}_{2}$ NCs flexible sheets with high dielectric permittivity and low loss factor have numerous applications in light emitting and energy storage devices. In this work, polymer-based $\mathrm{ZnO} / \mathrm{TiO}_{2} \mathrm{NCs}$ are synthesized by co-precipitation technique. The development of various diffraction planes (X-rays diffraction analysis) related to $\mathrm{TiO}_{2}$ and $\mathrm{ZnO}$ phases confirms the synthesis of polycrystalline polymer-based $\mathrm{ZnO} / \mathrm{TiO}_{2} \mathrm{NCs}$. The crystallinity of various phases is associated with increasing $\mathrm{ZnO}$ nanofillers. The surface morphology (scanning electron microscopic analysis) comprising of nanoparticles of different shapes is associated with increasing amount of nanofillers. The EDX analysis confirms the presence of $\mathrm{Zn}, \mathrm{O}$ and $\mathrm{Ti}$ in the synthesized polymer-based $\mathrm{ZnO} / \mathrm{TiO}_{2}$ NCs. Dielectric measurements demonstrating the sharp increase in dielectric permittivity with relatively low dissipation factor of synthesized polymerbased $\mathrm{ZnO} / \mathrm{TiO}_{2} \mathrm{NCs}$ are associated with increasing amount of $\mathrm{ZnO}$ nanofillers. The static value of dielectric constant $\left(\varepsilon^{\prime}\right)$ at low frequency $(100 \mathrm{~Hz})$ is found to be 14.56 for sample having $10 \%$ $\mathrm{ZnO}$ nanofillers that is 2.11 times greater than pure PVDF and it shows relatively low value of dissipation factor. The observed $\sigma_{\mathrm{ac}}$ of synthesized polymer-based $\mathrm{ZnO} / \mathrm{TiO}_{2} \mathrm{NCs}$ at $3.0 \times 10^{5} \mathrm{~Hz}$ and $1.0 \times 10^{6} \mathrm{~Hz}$ are ranged from $3.75-9.79$ and $15.61-42.72 \mu \mathrm{S} / \mathrm{m}$ respectively. The decreasing complex impedance and increasing electric modulus further confirm that the synthesized polymer-based $\mathrm{ZnO} / \mathrm{TiO}_{2} \mathrm{NCs}$ flexible sheets are the promising candidate for better capacitive performance showing high strength and flexibility.
\end{abstract}

Keywords: Nanocomposite; Polymer; Conductivity; Impedance; Permittivity, Modulus 


\section{Introduction}

Polymeric nanocomposites (NCs) are more attractive due to their remarkable "dielctric, optical, mechanical and electrical" properties. The polymer-based NCs showed outstanding properties as compared to unalloyed polymer which may be due to microstrains, defects and residual stresses developed during synthesis process. The properties of polymer-based NCs depend on weight fraction of different nanofillers, microstructural features and interfacial areas. The large interfacial area between the polymer and nanofillers plays a vital role to enhance the various properties of polymer-based NCs because they have high aspect ratio as well as high surface area. The numerous surface properties of polymer-based NCs are related to used polymer, weight fraction of nanofillers and their uniform mixing viva synthesis process [1-5]. The more commonly used polymers to synthesized polymer-based NCs flexible sheets are polyvinyl alcohol (PVA), Polymethyl methacrylate (PMMA) and polyvinylidene difluoride (PVDF). Mallick et al [6] have synthesized the polymer-based titanium dioxide $\left(\mathrm{TiO}_{2}\right) \mathrm{NCs}$ flexible sheets and they said that the humidity sensor has shown linear and stable response over the investigated range of frequencies. They pointed out that the response and recovery times of polymer-based sensors were found to be $45 \mathrm{~s}$ and $11 \mathrm{~s}$ respectively. Ishaq et al [7] have synthesized the polymerbased NCs flexible sheets of high dielectric constant (70.4) and low leakage current (0.39) at the frequency of $100 \mathrm{~Hz}$. Such type of synthesized polymer-based flexible sheets can be used in electronic industry for the development of energy storage devices. Sugumaran et al [8] have synthesized PVA/PMMA-based $\mathrm{TiO}_{2}$ NCs flexible sheets having high dielectric constants (24.6/26.8), low dielectric loss $(0.1-1 / 0.1-0.8)$ and refractive index $(1.6 / 2.3)$ respectively at the frequency of $1 \mathrm{KHz}$.

Amid polymers, PVDF is a lightweight and hydrophobic polymer due to low-cost, mechanical flexibility, low-temperature processing, ferroelectricity, high dielectric constant, high chemical resistive, more thermally stable and biocompatible. It is known that the $\mathrm{TiO}_{2}$ a most promising semiconducting material with high optical energy band gap, excellent optical transmittance, high refractive index and good dielectric properties [9]. The zinc oxide ( $\mathrm{ZnO})$, a semiconducting material with remarkable properties is being used in solar cell applications [10]. One of the most important characteristics of polymer-based NCs flexible sheets is their dielectric properties like dielectric constant, dielectric loss, loss factor, AC conductivity, impedance, however these properties intensely are depended on the size, shape, distribution of nanofillers, formation of 
bonds between nanofillers and polymer hydroxyl groups, microstructural features, interfical area between nanofillers and polymer matrix. Moreover the conductivity of nanofillers also plays a vital role to improve the surface properties of polymer-based NCs flexsible sheets. The outstanding properties of polymers-based NCs flexible sheets are associated to the complex motion of nanoparticles through molecular relaxations creating significant transitions whereas the polymeric interfaces behave as charge carrier trapping sites. It is important to study the effect of interfaces on the generation, transportation and storage of charge carrier in polymer matrix [11].

According to our knowledge, few research work has been done on the synthesis of polymerbased $\mathrm{ZnO}-\mathrm{TiO}_{2} \mathrm{NCs}$ flexible sheets. Therefore, it is necessary to synthsize the said polymerbased NCs and the optimization of various properties depending on the concentration of nanofillers and their sizes, stirring temperature and time. The polymer-based $\mathrm{ZnO}_{-} \mathrm{TiO}_{2} \mathrm{NCs}$ flexible sheets are being synthesized via different methods like sol-gel, hydrothermal, spin coating and co-pricipitations.

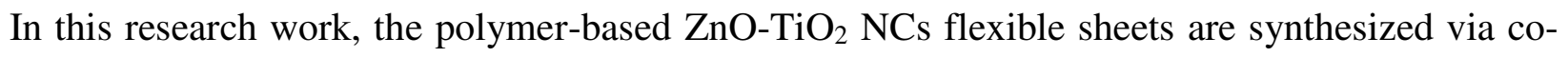
pricipitation method. The synthesized polymer-based $\mathrm{ZnO}^{-\mathrm{TiO}_{2}} \mathrm{NCs}$ flexible sheets are characterized by X-rays diffraction (XRD), scanning electron microscopy (SEM) , energy dispersive X-rays spectroscopy (EDX) and LC spectrometer in order to investigate the crystal structure, surface morphology, elemental composition and dielectric properties respectively.

\section{Experimental Setup}

The flexible sheets of polymer-based $\mathrm{ZnO}-\mathrm{TiO}_{2} \mathrm{NCs}$ (dimensions; $\sim 0.5 \mathrm{~mm} \times 1 \mathrm{~cm} \times 1 \mathrm{~cm}$ ) are synthesized via co-precipitation technique. The source materiasl used to synthesis the flexible sheets of polymer-based $\mathrm{ZnO}-\mathrm{TiO}_{2} \mathrm{NCs}$ are $\mathrm{PVDF}, \mathrm{ZnO}$ and $\mathrm{TiO}_{2}$ of analytical grade. The weight fractions of source materials are measured by using digital weight balance. Table 1 shows the composition of synthesized (A-1, A-2, A-3 and A-4) samples. Figure 1 demonstrates the schematic diagram of synthesis process of polymer-based $\mathrm{ZnO}^{-\mathrm{TiO}_{2}} \mathrm{NCs}$ flexible sheets. The synthesis process consists of various steps (i) for sample A-1 (only PVDF), (ii) for sample A-2, A-3 and A-4, the $\mathrm{ZnO}$ and $\mathrm{TiO}_{2}$ nanofillers are dissolved into $20 \mathrm{ml}$ solvent (dimethyleformamide: DMF) along with PVDF according to the composition given in table 1 and stirred them at $\sim 55{ }^{\circ} \mathrm{C}$ for $6 \mathrm{hrs}$. A gel type solution is formed which is converted into particular shape by using specific dies which then placed into oven at $\sim 55^{\circ} \mathrm{C}$ for $10 \mathrm{hrs}$ results in the formation 
of flexible sheets. These synthesized flexible sheets are characterized by using XRD, SEM, EDX and LC spectrometer in order to study the crystal structure, surface morphology, elemental composition, electrical and dielectric properties.

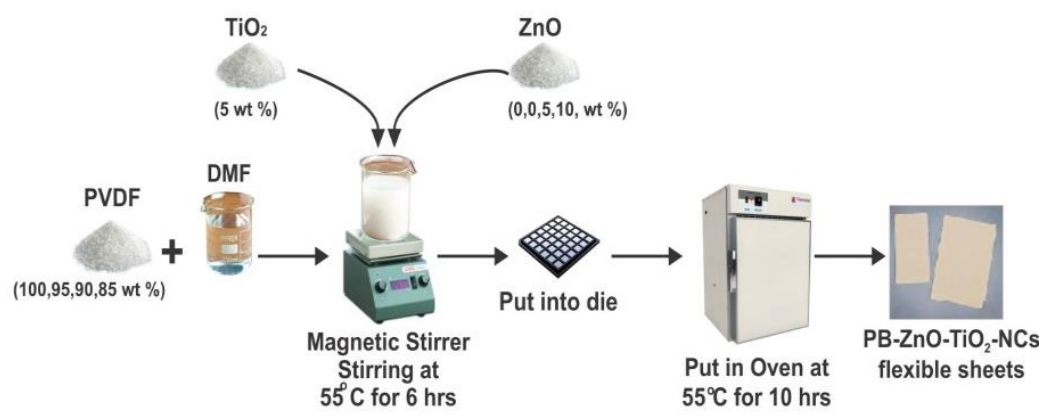

Figure 1. Schematic diagram of synthesis process for polymer-based $\mathrm{ZnO}-\mathrm{TiO}_{2} \mathrm{NCs}_{\text {flexible }}$ sheets.

\begin{tabular}{|c|c|c|c|c|}
\hline Sample & $\begin{array}{c}\text { Solvent } \\
(\mathrm{ml})\end{array}$ & $\begin{array}{c}\text { PVDF } \\
(\%)\end{array}$ & $\begin{array}{c}\mathrm{TiO}_{2} \\
(\%)\end{array}$ & $\begin{array}{c}\mathrm{ZnO} \\
(\%)\end{array}$ \\
\hline A-1 & 20 & 100 & 0 & 0 \\
\hline A-2 & 20 & 95 & 5 & 0 \\
\hline A-3 & 20 & 90 & 5 & 5 \\
\hline A-4 & 20 & 85 & 5 & 10 \\
\hline
\end{tabular}

Table 1: Composition of polymer-based $\mathrm{ZnO}-\mathrm{TiO}_{2} \mathrm{NCs}$ flexible sheets

\section{Result and discusstion}

\subsection{Structural analysis}

The XRD analysis is used to study the crystal structure of flexible sheets of polymer-based $\mathrm{ZnO}$ $\mathrm{TiO}_{2} \mathrm{NCs}$ synthesized at various compostions of PVDF and $\mathrm{ZnO}$ nanofillers for fixed amount of $\mathrm{TiO}_{2}$. Table 1 shows the wt.\% of PVDF, $\mathrm{ZnO}$ and $\mathrm{TiO}_{2}$ used to synthesized different (A-1, A-2, A-3 and A-4) samples. The average crystallite size (C. S) of $\mathrm{ZnO}$ (101) plane is calculated by using the following relation

$$
\text { C. } S=\frac{k \lambda}{F W H M \cos \theta}
$$

Where $\lambda=1.54 \AA$ (wavelength of incident radiation) and $k=0.99$ (numerical constant). The microstrains produced in $\mathrm{ZnO}$ (101) plane is estimated by using following relation. 


$$
\text { Microstrain }=\frac{F W H M \cos \theta}{4}
$$

The dislocation density $(\delta)$ is defined as the length of dislocation lines per unit volume which can be calculated by employing the following relation [12].

$$
\delta=\frac{1}{(c . s)^{2}}
$$

Figure 2 reveals the XRD patterns of flexible sheets of polymer-based $\mathrm{ZnO}^{-\mathrm{TiO}_{2}} \mathrm{NCs}$ synthesized by co-precipation technique. The polymer-based ${\mathrm{ZnO}-\mathrm{TiO}_{2}} \mathrm{NCs}$ are synthesized according to the compositions mentioned in table 1. The XRD pattern of sample A-1 shows the development of broad hump ( $2 \theta$ angle ranged from 10 to 23 degree). This shows that the used polymer is amorphous or poor crystalline in nature and the appearance of no diffraction peak related to any other phase indicates the purity of PVDF. The XRD pattern of sample A-2 reveals the development of $\mathrm{TiO}_{2}(105)$ plane $\left(2 \theta=56.87^{\circ}\right)$ with weak crystallinity (since the peak intensity is weak), however its development decreases the hump (PVDF).

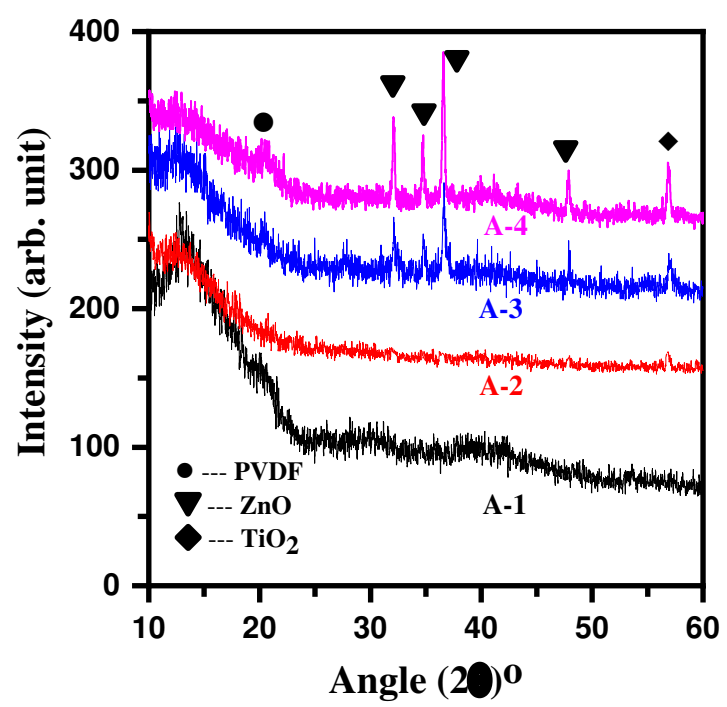

Figure 2: XRD patterns of flexible sheets of polymer-based ${\mathrm{ZnO}-\mathrm{TiO}_{2} \mathrm{NCs}}^{\mathrm{N}}$

The XRD pattern of sample A-3 exhibits the development of (100), (002), (101), (102) and (105) diffraction planes related to $\mathrm{ZnO}$ and $\mathrm{TiO}_{2}$ phases. The XRD pattern of sample A-4 exhibits that the intensity of previously observed diffraction planes is increased. In short, the intensity of all diffraction peaks is increased with increasing the wt.\% of $\mathrm{ZnO}$ nanofillers. 


\begin{tabular}{|c|c|c|c|c|c|c|c|}
\hline Samples & Phase & h k l & $\begin{array}{l}\text { Angle } \\
(2 \theta)_{\text {obs. }}\end{array}$ & FWHM & Intensity & $\begin{array}{l}\text { C.S } \\
(\mathrm{nm})\end{array}$ & $\begin{array}{l}\text { Micro- } \\
\text { stains }\end{array}$ \\
\hline A-1 & PVDF & --- & --- & --- & --- & --- & --- \\
\hline A-2 & $\mathrm{TiO}_{2}$ & 105 & 57.9 & 0.307 & 14.22 & 397.61 & 0.042 \\
\hline \multirow[t]{5}{*}{ A-3 } & \multirow[t]{4}{*}{$\mathrm{ZnO}$} & 100 & 32.09 & 0.308 & 32.09 & 333.77 & 0.065 \\
\hline & & 002 & 34.91 & 0.258 & 21.58 & 411.66 & 0.053 \\
\hline & & 101 & 36.57 & 0.371 & 41.98 & 292.31 & 0.074 \\
\hline & & 102 & 47.86 & 0.205 & 10.29 & 633.22 & 0.034 \\
\hline & $\mathrm{TiO}_{2}$ & 105 & 57.9 & 0.398 & 15.95 & 401.90 & 0.054 \\
\hline \multirow[t]{5}{*}{ A- 4} & \multirow[t]{4}{*}{$\mathrm{ZnO}$} & 100 & 32.09 & 0.231 & 54.36 & 445.03 & 0.049 \\
\hline & & 002 & 34.72 & 0.22 & 37.09 & 481.65 & 0.045 \\
\hline & & 101 & 36.57 & 0.241 & 98.11 & 449.98 & 0.048 \\
\hline & & 102 & 47.86 & 0.264 & 24.49 & 491.70 & 0.044 \\
\hline & $\mathrm{TiO}_{2}$ & 105 & 57.9 & 0.312 & 33.51 & 525.32 & 0.041 \\
\hline
\end{tabular}

Table 2: Various structural parameters of flexible sheets of polymer-based $\mathrm{ZnO}-\mathrm{TiO}_{2} \mathrm{NCs}$ Moreover, the intensity of $\mathrm{TiO}_{2}$ (105) plane is increased with increasing wt.\% of $\mathrm{ZnO}$

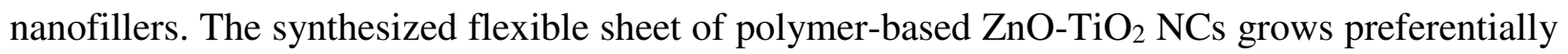
along (101) orientation because the intensity of (101) plane is maximum. We hypothesised that the amount of energy transferred to flexible sheets of NCs is associated with the increasing amount of $\mathrm{ZnO}$ nanofillers, the fraction of this transfer of energy may be used to increase the growth of $\mathrm{TiO}_{2}$ phase results in the increase of peak intensity. The intensity of hump related to PVDF phase is decreased first with the addition of $\mathrm{TiO}_{2}$ nanofillers which is further decreased with increasing wt.\% of $\mathrm{ZnO}$ nanofillers. Table 2 demonstarets the different structural parameters like phase identification, h k 1, FWHM, C. S, peak intensity and microstrains developed due to increasing wt.\% of $\mathrm{ZnO}$ nanofillers in polymer-based $\mathrm{ZnO}-\mathrm{TiO}_{2} \mathrm{NCs}$.

\subsection{SEM analysis}

The SEM analysis is used to study the microstructural features of PVDF and polymer-based $\mathrm{ZnO}_{-} \mathrm{TiO}_{2}$ NCs. Figure 3 demonstartes the microstructures of PVDF and polymer-based $\mathrm{ZnO}-$ $\mathrm{TiO}_{2}$ NCs synthesized according the compositions mentioned in table 1 . The SEM microstructure of sample A-1 (figure $3 \mathrm{~A}$ ) indicates the formation of dense microstructure along with the appearance of few strips (length $=2$ micron, width $=500-800 \mathrm{~nm}$ ) which may arises during mixing of polymer into solvent. The SEM microstructure of sample A-2 (figure $3_{\mathrm{B}}$ ) shows the formation of elongated rods of different shapes, rounded nano-particles forming grapes like 
clusters and strips of various lengths and widths which are embeaded into dense microstricture of polymer matrix. The SEM microstructure of sample A-3 (figure 3C) exhibits the formation of rounded nano-particles (diameter $\sim 200-500 \mathrm{~nm}$ ) forming leaf like microstructure comprising of rounded nno-particles. All these microstructural features are embeaded into dense microstructure of polymer matrix. The SEM microstructure of sample A-4 (figure $3 \mathrm{D}$ ) reveals the formation of rounded nano-particles (diameter $\sim 100-400 \mathrm{~nm}$ ), nano-rods (length $\sim 1-2.5$ micron, diameter $\sim$ 200-400 nm). The outlook appearance of microstructure comprising of rounded nanoparticles and nanorods confirms the formation of complicated microstructure with rough surface. Few hills like microstructures are also observed. Results show that the change in surface morphology of synthesized polymer-based NCs is associated with the increase of wt. $\%$ of nanofillers.

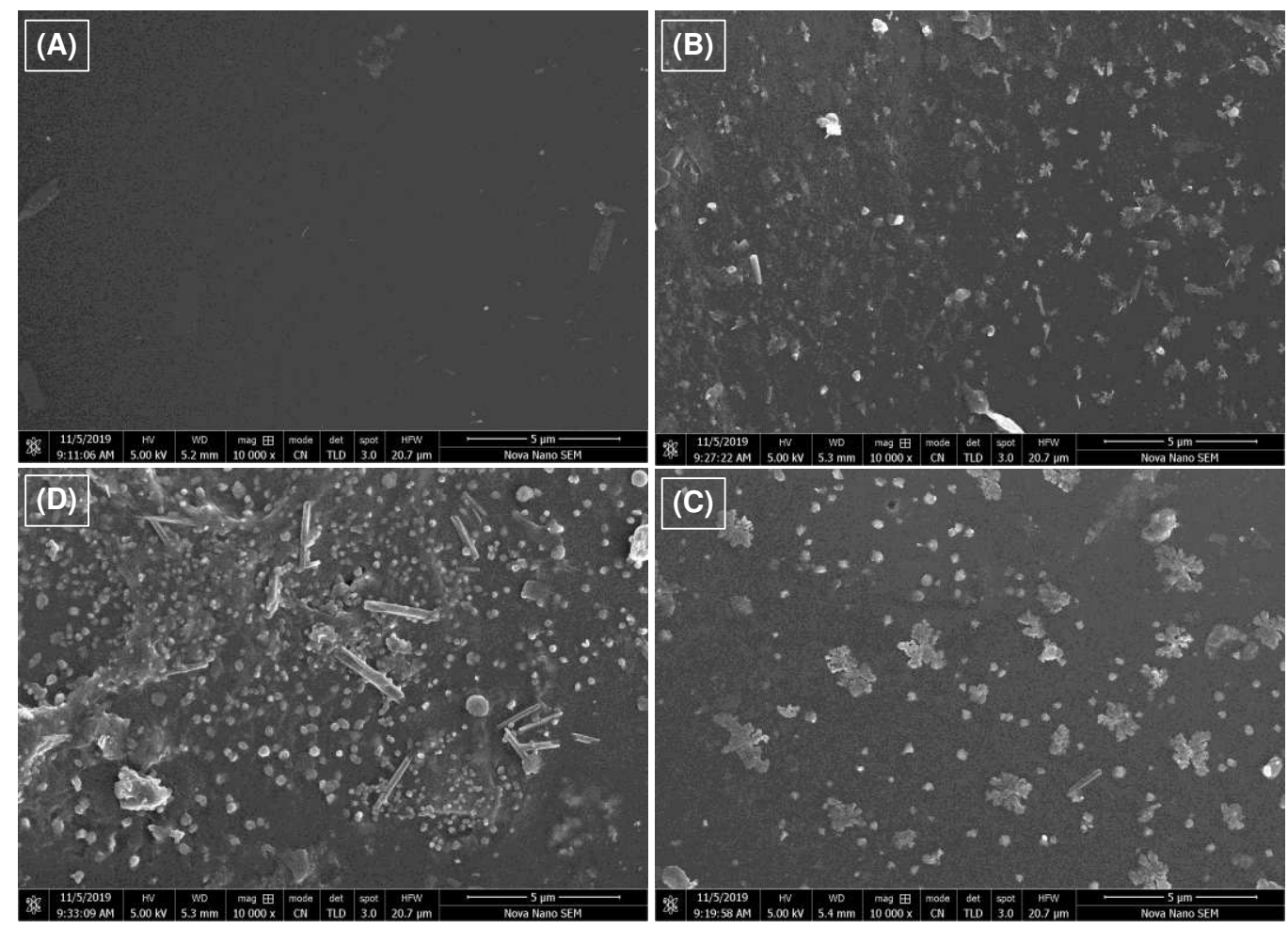

Figure 3: SEM microstructures of: (A) A-1, (B) A-2, (C) A-3 and (D) A-4 of flexible sheets of polymer-based $\mathrm{ZnO}^{-\mathrm{TiO}_{2}} \mathrm{NCs}$

Figure 4 demonstartes the EDX spectrum of polymer-based $\mathrm{ZnO}-\mathrm{TiO}_{2}$ NCs (sample A-4, table 1). The development of various peaks confirms the presence of $\mathrm{O}, \mathrm{C}, \mathrm{Ti}$ and $\mathrm{Zn}$ in the synthesized sample. Table 3 shows the wt.\% of O, C, Ti and $\mathrm{Zn}$ present in the synthesized flexible sheets of polymer-based NCs. 


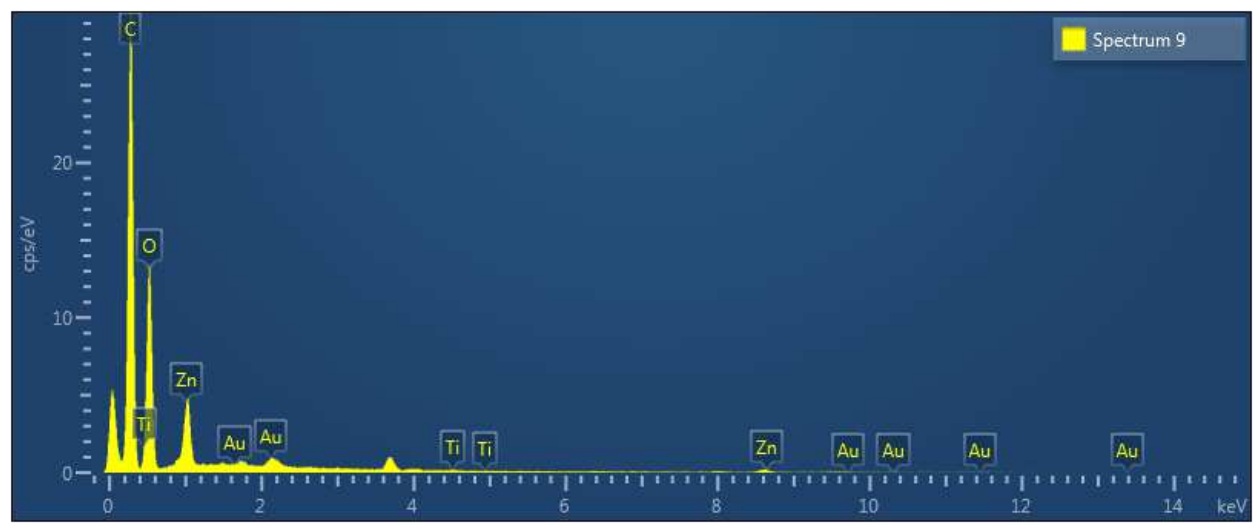

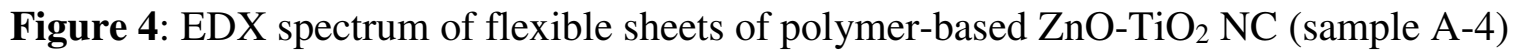

\begin{tabular}{|c|c|c|c|c|}
\hline \multirow{2}{*}{ Samples } & \multicolumn{4}{|c|}{$\begin{array}{c}\text { Elemental compositions (wt.\%) of PVDF } \\
\text { and polymer-based } \mathrm{ZnO}-T i O_{2} \text { NCs }\end{array}$} \\
\cline { 2 - 5 } & $\mathrm{O}$ & $\mathrm{C}$ & $\mathrm{Ti}$ & $\mathrm{Zn}$ \\
\hline $\mathrm{A}-1$ & 41.99 & 57.28 & ----- & ----- \\
\hline $\mathrm{A}-2$ & 39.44 & 56.11 & 0.15 & ----- \\
\hline $\mathrm{A}-3$ & 37.47 & 55.35 & 0.16 & 2.71 \\
\hline $\mathrm{A}-4$ & 35.91 & 54.52 & 0.17 & 5.87 \\
\hline
\end{tabular}

Table 3: shows the elemental compositions of $\mathrm{O}, \mathrm{C}, \mathrm{Ti}$ and $\mathrm{Zn}$ elements present in the synthesized flexible sheets of polymer-based NCs

\subsection{Dielectric and electrical analysis}

The dielectric permittivity of real $\left(\varepsilon^{\prime}\right)$ and imaginary $\left(\varepsilon^{\prime \prime}\right)$ parts can be calculated by the following formulas.

$$
\begin{gathered}
\varepsilon^{*}=\varepsilon^{\prime}-j \varepsilon^{\prime \prime} \\
\varepsilon^{\prime}=\frac{c d}{A \varepsilon_{o}} \\
\varepsilon^{\prime \prime}=\varepsilon^{\prime}(D f)
\end{gathered}
$$

Where $C, d, \varepsilon_{o}$ and $A$ are the capacitance, thickness, permittivity of free space $\left(8.85 \times 10^{-12} \mathrm{~F} / \mathrm{m}\right)$ and area of flexible sheets polymer-based NCs respectively where $\mathrm{j}=(-1)^{1 / 2}$ [13].

Figure 5 exhibits the variation of dielectric constant $\left(\varepsilon^{\prime}\right)$, dielectric loss $\left(\varepsilon^{\prime \prime}\right)$ of flexible sheets of polymer-based NCs as a function of frequency of applied filed and increasing wt.\% of 
nanofillers. It is found that the values of $\varepsilon^{\prime}$ are decreased gradually with increasing frequency. The values of $\varepsilon^{\prime}$ at $100 \mathrm{~Hz}$ are found to be 6.87, 9.10, 13.96 and 14.56 corresponding to samples A-1, A-2, A-3 and A-4 respectively which indicate that the values of $\varepsilon^{\prime}$ of polymer-based NCs are increased with increasing wt.\% of nanofillers. The higher values of $\varepsilon^{\prime}$ are due to slow electric filed in low frequency range which provides sufficient time for both permanent and induced dipoles to align themselves which enhances the interfacial polarization (IP) so called Maxwell Wagner Sillars (MWS) effect [14]. This effect becomes more prominent as the wt.\% of nanofillers is increased in polymer-based NCs. We hypothesized that the increasing wt.\% of nanofillers (either $\mathrm{TiO}_{2}$ or $\mathrm{ZnO}$ ) into polymer matrix is responsible to increase the viscosity of polymer matrix providing more time for both permamnent and indices dipoles alignment, enhancing the IP effects and hence increases the values of $\varepsilon^{\prime}$ [15]. The induce dipoles aligment and increasing IP effects may be associated with the formation of nanocrystallites creating more crystallite boundaries and development of microstrains which are responsioble to slow the electric field at low frequency and hence increase the values of $\varepsilon^{\prime}$ of polymer-based $\mathrm{ZnO}^{-} \mathrm{TiO}_{2}$ NC. On the other hand, as the frequency is increased, the electric field is changed rapidly in short time and hence the dipoles (permanent and indiced) could not align themselves, reduces the IP effect and decreases the values of $\varepsilon^{\prime}$ of polymer-based NCs. It is obvious that the values $\varepsilon^{\prime}$ of polymer-based NCs remain higher than pure polymer for all frequency range. The values of $\varepsilon^{\prime}$ of polymer-based NCs [PVDF (85\%), $\mathrm{TiO}_{2}(5 \%)$ and $\left.\mathrm{ZnO}(10 \%)\right]$ is found to be 14.56 which is 2.11 times higher than pure polymer at $\sim 100 \mathrm{~Hz}$. The values of $\varepsilon^{\prime}$ of polymer-based NCs is found to be 11.24 which is $\sim 2.16$ times higher than pure polymer at $\sim 10^{6} \mathrm{~Hz}$. It is well known that the increasing values of $\varepsilon^{\prime}$ are due to increasing IP effect and AC conductivity (discuss later) whereas IP increases due to the greater number of free charges forming dipoles at the interfaces of polymer and nano-fillers. The various interfaces may be formed between the polymer and different types of nanofillers which play an important role to increase the number of free charges which increase the IP effect and hence increase the values of $\varepsilon^{\prime}$ and AC conductivity [16,17].

Figure $5 \mathrm{~B}$ demonstrated the variation of dielctric loss as a function of increasing frequency. The values of $\varepsilon^{\prime \prime}$ (sample A-1) at $100 \mathrm{~Hz}$ is found to be 0.925 which decreases sharply and becomes equal to 0.108 at same frequency. This value of $\varepsilon^{\prime \prime}$ is slighlty increased with increasing frequency and found to be 0.369 at $10^{6} \mathrm{~Hz}$. The values of $\varepsilon^{\prime \prime}$ (sample A-2) at $100 \mathrm{~Hz}$ is found to be 1.529 which decreases sharply and becomes equal to 0.303 at same frequency. This value of $\varepsilon^{\prime \prime}$ is 
slighlty increased with increasing frequency and found to be 0.536 at $10^{6} \mathrm{~Hz}$. The values of $\varepsilon^{\prime \prime}$ (sample A-3) at $100 \mathrm{~Hz}$ is found to be 2.318 which decreases sharply and becomes equal to 0.397 at same frequency. This value of $\varepsilon^{\prime \prime}$ is slighlty increased with increasing frequency and found to be 0.749 at $10^{6} \mathrm{~Hz}$. The values of $\varepsilon^{\prime \prime}$ (sample A-4) at $100 \mathrm{~Hz}$ is found to be 5.811 which decreases sharply and becomes equal to 1.979 at same frequency and there is no change with increasing frequency.
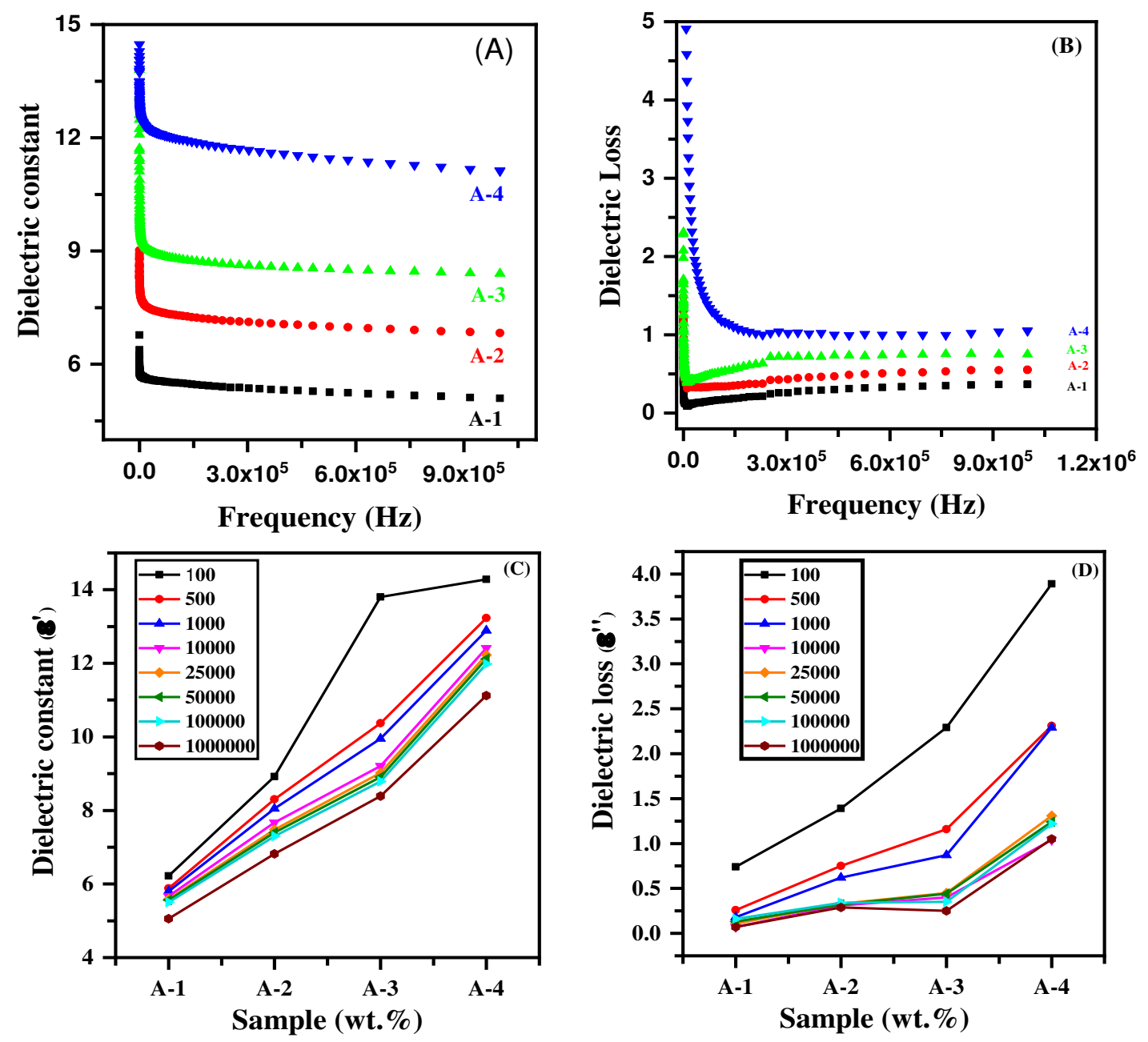

Figure 5: Variation of $\varepsilon^{\prime}(\mathrm{A}, \mathrm{C})$ and $\varepsilon^{\prime \prime}(\mathrm{B}, \mathrm{D})$ of flexible sheets of polymer-based $\mathrm{ZnO}-\mathrm{TiO}_{2} \mathrm{NCs}$ as a function of frequency of applied filed and increasing wt.\% of nanofillers respectively

Figure $5(\mathrm{C}, \mathrm{D})$ demonstrate the variation of $\varepsilon^{\prime}$ and $\varepsilon^{\prime \prime}$ of polymer-based NCs as a fuction of increasing wt.\% of nanofillers. The values of $\varepsilon^{\prime}$ and $\varepsilon^{\prime \prime}$ are increased gradually with increasing wt.\% of nanofillers while they are decreased with increasing frequency. The decreasing behavior 
of $\varepsilon^{\prime}$ and $\varepsilon^{\prime \prime}$ of polymer-based NCs is due to the reduction of particle size as well as increasing porosity of synthesized flexible sheets with increasing wt.\% of nanofillers [18].

In order to observe the conducting behavior of synthesized polymer-based NCs then we have to determine the parameters that may control the conduction mechanism of polymer-based NCs. The AC conductivity $\left(\sigma_{\mathrm{ac}}\right)$ of synthesized polymer-based NCs is calculated by using the flowing relation [19].

$$
\sigma_{a c=\varepsilon_{o} \varepsilon^{\prime}} \omega(\tan \delta)
$$

Where $\omega=2 \pi \mathrm{f}$ and $\tan \delta$ is the dissipation factor.

Figure 6 shows the variation of $\sigma_{\mathrm{ac}}$ of polymer-based NCs with increasing frequency and wt.\% of nanofillers. The values of $\sigma_{\mathrm{ac}}$ of synthesized polymer-based NCs are increased with increasing frequency while there is no increasing/decreasing trend is observed in the values of $\sigma_{\mathrm{ac}}$ with increasing wt.\% of nanofillers. The values of $\sigma_{\mathrm{ac}}$ of synthesized flexible sheets at $3.0 \times 10^{5} \mathrm{~Hz}$ and $1.0 \times 10^{6} \mathrm{~Hz}$ are ranged from $3.75-9.79$ and $15.61-42.72 \mu \mathrm{S} / \mathrm{m}$ respectively.

Nasir et al [20] have reported that the electrical conduction mechanism is related to the elelctrons and polaron hopping mechanism which can act as hopping channels. The increasing frequency facilitates the conductive channels and hence promots the hopping of charge carrier's. Therefore, the increasing $\sigma_{\mathrm{ac}}$ of synthesized flexible sheets is due to conduction mechanism occured due to small polaron hopping.

Furthermore, the increasing behavior of $\sigma_{\mathrm{ac}}$ with increasing frequency is devided into two regions (region $\mathrm{I}=$ up to $2.0 \times 10^{5} \mathrm{~Hz}$ and region $\mathrm{II}=$ from $2.0 \times 10^{5}$ to $1.0 \times 10^{6} \mathrm{~Hz}$ ). In region $\mathrm{I}$, the conductivity plot is frequency independent while in region II, it is frequency dependent, however, after region I, the conductivity starts to increase with increasing frequency [21]. The increasing conductivity of synthesized flexible sheets of polymer-based NCs may be decribed by Jonscher's Power Law [22].

$$
\sigma_{\omega}=\sigma_{o}+A \omega^{n}
$$

This law indicate that the first term is frequency independent while second term is frequency dependent at lower and higher frequencies respectively. In second term, $A, \omega$ and $\mathrm{n}$ are constant amplitude, angular frequency and slope of frequency dependent conductivity curve. The value of $n$ is associated with the increasing wt.\% of nanofillers which can be found by using the slope of conductivity curves. It is clear that in region I, no change in the value of $n$ 
with increasing wt.\% of nanofillers showing non-equilibrium possession of traped charge carrier's, whereas, in region II, the values of $n$ are found to be increased with increasing wt.\% of nanofillers as well as frequency. It means that the charge carrier's are trapped in low frequency region (region I) whereas the charge carrier's are not trapped in high frequency region (region II). These non-trapped localized charge carrier's causes to dielctric relaxation as well as increases the conduction of synthesized flexible sheets of polymer-based NCs due to short range translational hopping of small polarons [23].

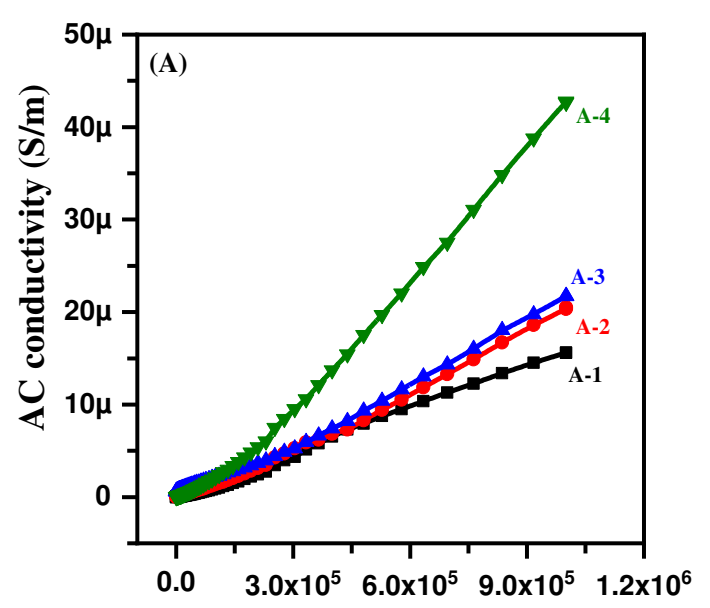

Frequency $(\mathrm{Hz})$

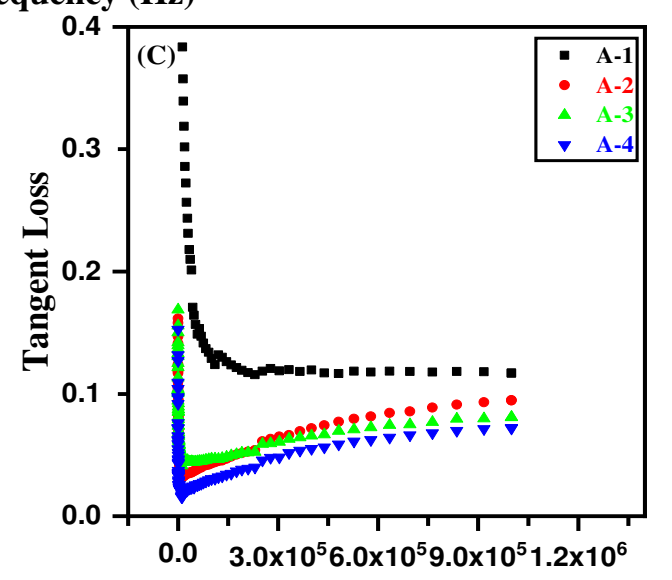

Frequency $(\mathrm{Hz})$

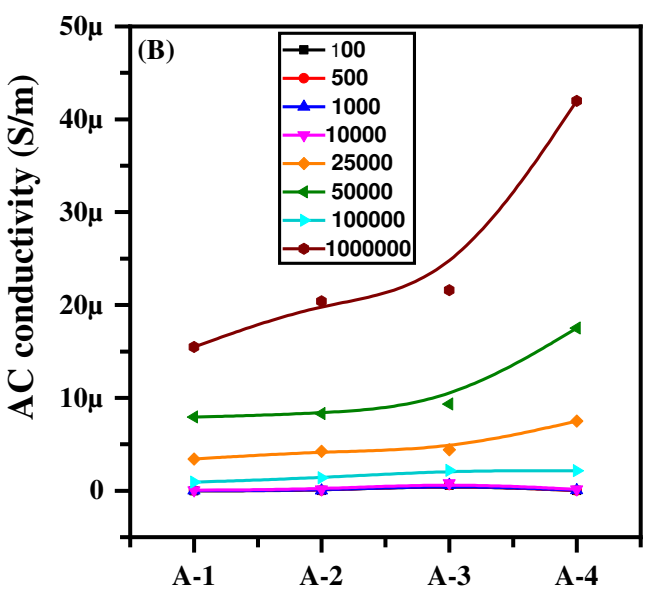

Sample (wt.\%)

Figure 6: Variation of (A) $\sigma_{\mathrm{ac}}$ and (C) tangent loss of polymer-based $\mathrm{ZnO}-\mathrm{TiO}_{2} \mathrm{NCs}$ as a function of increasing frequency and variation of $\sigma_{\mathrm{ac}}(\mathrm{B})$ as a function of increasing wt. $\%$ of nanofillers

It has been reported that [24-25] the $\sigma_{\mathrm{ac}}$ is increased with increasing temperature which is attributed to dislocations at interface of involved constituents. In our case, the mixing of nanofillers into PVDF matrix is responsible to generate dislocations at the interface of 
involved constituents and hence increases the conduction behavior of synthesized flexible sheets of polymer-based NCs. The frequency dependence of conductivity in relaxation phenomenon arises due to mobile charge carriers.

The PVDF is not much compact, so its particles are randomly oriented. The linkage amid the particles through grain boundaries results in relatively low conductivity. The inorganic nanofillers like $\mathrm{TiO}_{2}, \mathrm{ZnO}$ or $\mathrm{TiO}_{2}+\mathrm{ZnO}$ are heavier than PVDF, therefore, when these nanofillers are mixed with PVDF chains results in the formation of compact NCs materials. The mixing of nanofillers improves the weak links between the PVDF chains and the coupling through grains boundaries which eventually results in improved conductivity of synthesized polymer-based NCs. Therefore, the addition of $\mathrm{TiO}_{2}+\mathrm{ZnO}$ into PVDF matrix is responsible to improve the weak links between the involved constituent, results in the formation of compact flexible sheets with larger non-traped charge carriers at higher frequency and hence enhances the conductivity of synthesized polymer-based NCs [26, 27]. Figure 6-B indicates the variation of $\sigma_{\mathrm{ac}}$ of polymer-based NCs as a function of increasing wt.\% of nanofillers. The $\sigma_{\mathrm{ac}}$ is very low at $10^{4} \mathrm{~Hz}$ while it is increased with the further increase of frequency. Figure 6-C indicates the variation of tangent loss as a function of increasing frequency. It is clear that the tangent loss is decreased with increasing wt.\% of nanofillers while it is slightly increase with increasing frequency, however, the tangent loss is sharply decreased in low frequency region. It is found that the tangent loss of all samples containg nanofillers is lower than PVDF. The decrase in tagnet loss indicates the increase of conductivity of synthesized polymer-based NCs, whereas the increasing conductivity is responsible to increase the elelctrical properties .

The complex impedance $\left(Z^{*}\right)$ spectroscopy is used to study the electrical conduction mechanism in different phases of polycrystalline materials. The real $\left(Z^{\prime}\right)$ and imaginary $\left(Z^{\prime \prime}\right)$ parts of $Z^{*}$ of polymer-based NCs are calculated by using following relations.

$$
\begin{gathered}
Z^{*}=Z^{\prime}+j Z^{\prime \prime} \\
Z^{\prime}=Z \cos \theta \\
Z^{\prime \prime}=Z \sin \theta
\end{gathered}
$$

where $\mathrm{j}=(-1)^{1 / 2}$

Figure 7 demonstrates that the values of $Z^{\prime}$ and $Z^{\prime \prime}$ of synthesized polymer-based NCs with increasing frequency and wt.\% of nanofillers. The values of these parameters are sharply 
decreased at low frequency but there is a smaller change with increasing frequency (inset plot), however, it seems to becomes frequency independent at high frequency. Such type of variation in these parameters is agreed well with the literature. Atiq et al. have [28] reported that the availability of more non-traped charge carriers are responsible to increase the conduction in the synthesized polymer-based NCs with increasing frequency. It means that the impedence of polymer-based NCs is decreased with increasing frequency.
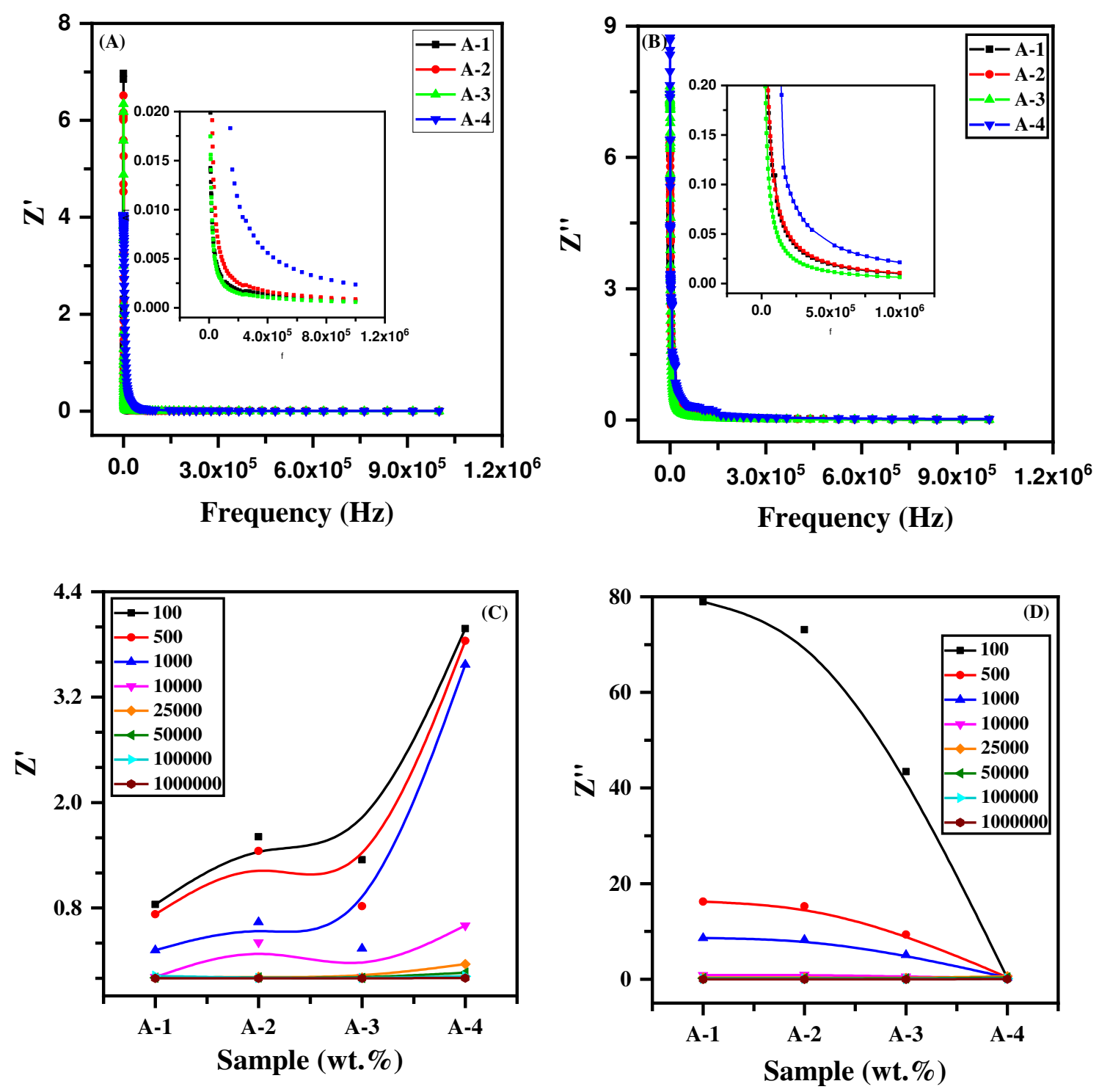

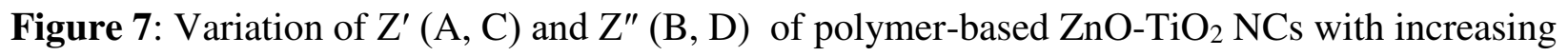
frequency of applied field and with increasing wt.\% of nanofillers respectively 
Batoo et al. [29] have demonstrates that the decreasing values of $Z^{\prime}$ and $Z^{\prime \prime}$ with increasing frequency is responsible to increase the conduction of synthesized flexible sheets which is due to hopping of electron between localized ions which are increased with increasing frequency. Singh et al. [30] have reported that the $Z^{\prime}$ and $Z^{\prime \prime}$ parameters become frequency independent in high frequency region which is agreed well with our results. However, a small change in these parameters with increasing frequency may be due to mixing of nanofillers and corresponding transfer of their energy to polymer matrix.

According to heterogeneous model, the polycrystalline materials are composed of grains which are isolated through grain boundaries. It is known that the grain boundaries are more resistive as compare to grains because of more disordering atomic arrangement near the grain boundaries and hence increases the resistivity. In our case, the formed rounded nanoparticles, nanorods and nanostrips of polymer-based NCs are embedded into PVDF matrix causes to produce defects, microstrains and grain boundaries and hence the synthesized flexible sheets of polymer-based NCs becomes more resistive. These grain boundaries between the nanoparticles are increased with increasing wt.\% of nanofillers, enhances the electron scattering mechanism results in the increase of resistivity at low frequency. Complex impedance analysis is a significant technique to distinguish the transport characteristics occurring between the grains and grain boundaries and explains the changes observed in the dielectric permittivity, dielectric losses and conductivity of materials $[31,32]$. The impedance of material can be measured by series or parallel combination of RC equivalent circuit. Electrical properties of materials are also calculated in terms of complex impedance $\left(Z^{*}\right)$. Figure $7(\mathrm{C}, \mathrm{D})$ exibits the comprehensive understanding about the variation in $Z^{\prime}$ and $Z^{\prime \prime}$ parameters for all samples at different frequencies. The values of $Z^{\prime}$ are increased with increasing wt.\% of nanofillers while they are decreased with increasing frequency. The values of $Z^{\prime \prime}$ are exponentially decreased with increasing wt.\% of nanofillers while they are decreased with increasing frequency. The decreasing values of imaginary impedence part indicate the increase of electrical conductivity. 
The electrical modulus is used to explain transport of electrical charges to with in the dielectric medium. The complex modulus is inversely related to complex dielectric constant calculated by the relations:

$$
\begin{gathered}
M^{*}=M^{\prime}+j M^{\prime \prime}=1 / \varepsilon^{*} \\
\mathrm{M}^{\prime}=\varepsilon^{\prime} /\left(\varepsilon^{2}+\varepsilon^{\prime 2}\right) \\
\mathrm{M}^{\prime \prime}=\varepsilon^{\prime \prime} /\left(\varepsilon^{\prime 2}+\varepsilon^{\prime \prime 2}\right)
\end{gathered}
$$

where $\mathrm{M}^{\prime}$ is the real part and $\mathrm{M}^{\prime \prime}$ is the imaginary part of complex electric modulus. Figure 8 shows the variation of complex electric modulus for all compositions $\left(\mathrm{ZnO}, \mathrm{ZnO}+\mathrm{TiO}_{2}\right)$ with increasing frequency. The value of $\mathrm{M}^{\prime}$ shows a significant dispersion in lower frequency which increases. This asymptotic value of $\mathrm{M}^{\prime}$ depicts that the synthesized polymer-based NCs flexible sheets are capacitive in nature [33,34]. This increasing behavior shows the relaxation processes existing over extensive range of frequencies.
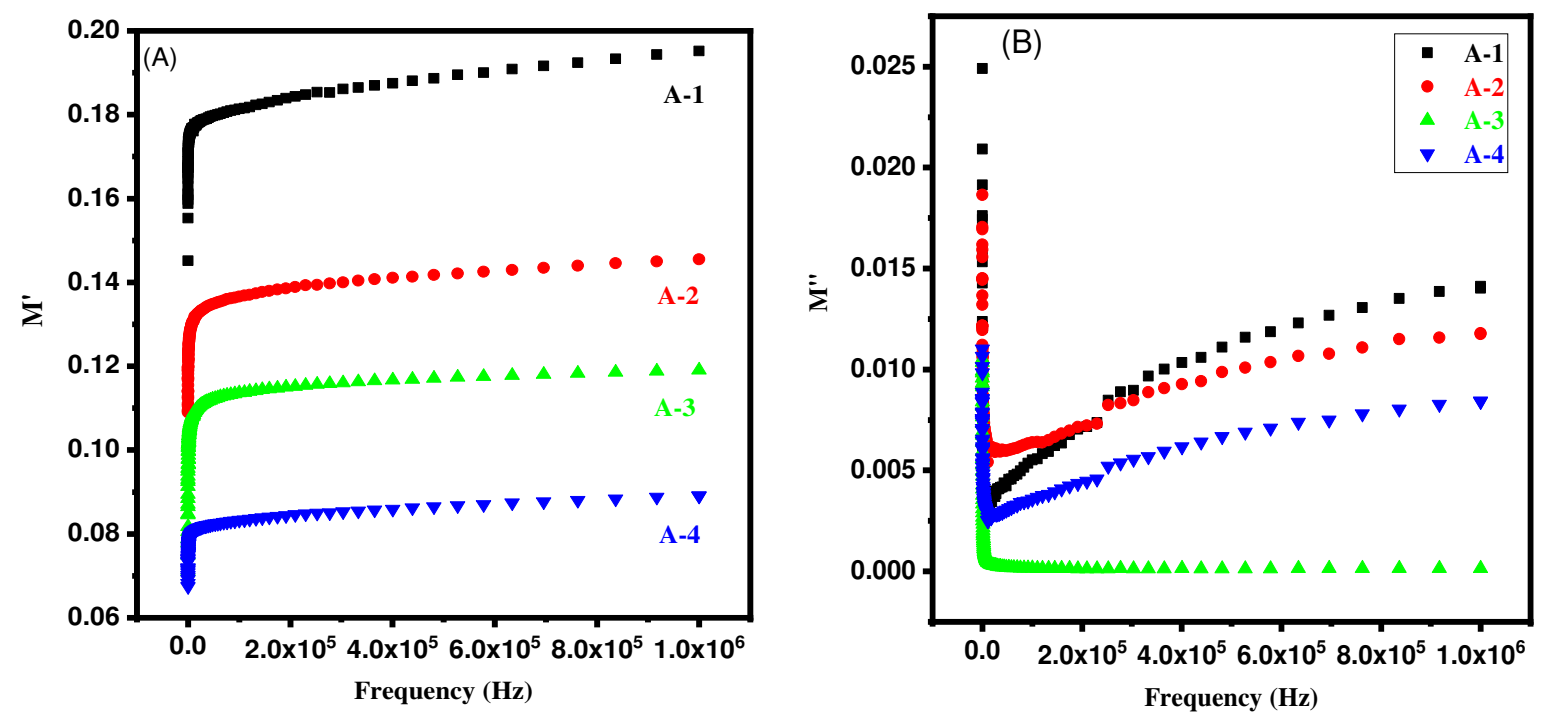

Figure 8 ( $\mathrm{A}, \mathrm{B})$ Variation in $\mathrm{M}^{\prime}$ and $\mathrm{M}^{\prime \prime}$ as a function of frequencies of flexible sheets of polymer-based $\mathrm{Zno}^{-\mathrm{TiO}_{2}} \mathrm{NCs}$

On the other hand, the values of $\mathrm{M}^{\prime \prime}$ are maximum in low frequency region showing relaxation phenomena because the charge carriers are mobile over long distance in low frequency region .The values of $\mathrm{M}^{\prime \prime}$ are decreased sharply in low frequency region, after that it starts to increase slightly with increased frequency because in high frequency region, the electric field is changed rapidly and the charge carrier are mobile over short distance .This increasing and decreasing dispersion phenomenon of $\mathrm{M}^{\prime \prime}$ for all samples shows the relaxation phenomena may be due to 
addition of various wt.\% of nanofillers and hence responsible to strengthen the polymer-based NCs flexible sheets as well as increases the dielectric permittivity [35]. Additionally, the value of complex modulus (below $10 \mathrm{kHz}$ for $\mathrm{M}^{\prime}$ and up to $1000 \mathrm{~Hz}$ for $\mathrm{M}^{\prime \prime}$ ) of polymer-based $\mathrm{NCs}$ at low frequency region indicates the removal of elelctrode polarization [36,37]. Figure 8 also reveals that the values of complex modulus $\left(\mathrm{M}^{\prime}\right.$ and $\left.\mathrm{M}^{\prime \prime}\right)$ are decreased significantly with increasing wt.\% of nanofillers which will effect on various dielectric and electrical properties of the synthesized polymer-based NCs.

Based on above discussion, we hypothesized that when $\mathrm{TiO}_{2}$ and $\mathrm{ZnO}$ nanofillers are mixed into PVDF matrix, the microcapacitors are formed within the polymer matrix where $\mathrm{ZnO}$ provides conducting pathways and acts as electrodes whereas the addition of $\mathrm{TiO}_{2}$ nanofillers increases the strength as well as insulating behavior of polymer-based NCs flexible sheets. The various contents nanofillers in polymer-based NCs flexible sheets enhances the formation of microcapacitors and hence it increases their $\varepsilon^{\prime}$ values. This increasing number of microcapacitors formation is responsible to increase the $\sigma_{\mathrm{ac}}$ of polymer based NCs flexible sheets at high frequencies. The formation of better network for charge transportation may be other reason to increase the $\sigma_{\mathrm{ac}}$ of polymer-based NCs flexible sheets. At low frequency, the formation of lower number of microcapacitors decreases the $\sigma_{\mathrm{ac}}$ and increases the dielectric constant. This increase in dielectric constant may also be due to the formation of more induce dipoles at low frequency. The values of $\mathrm{M}^{\prime}$ of polymer-based NCs (except pure PVDF) are relatively smaller in low frequency region because the smaller electric filed is not enough to mobile extra charge carriers over long distances due to mixing of various wt.\% of nanofillers. The polycrystalline materials are composed of grains, separated by grains boundaries. These grain boundaries are more resistive than grains due to disordering arrangement of atoms near grain boundaries which increases the electron scattering results in the increase of resistivity in low frequency region. This increase in resistivity decreases the $\sigma_{\mathrm{ac}}$ of polymer-based NCs. On the other hand, in high frequency region, the grain growth of polycrystalline materials decreases the number of grain boundaries and becomes less resistive, due to the formation of better network of microcapacitors which increases the $\sigma_{\mathrm{ac}}$ of polymer-based NCs. In short, the change in dielectric constant, loss tangent, AC conductivity, impedance and modulus of polymer-based NCs flexible sheets can be correlated with the formation of polycrystalline phase of $\mathrm{ZnO}$ in flexible sheets of polymer-based $\mathrm{ZnO} \mathrm{NCs}$ where the polycrystalline $\mathrm{ZnO}$ phase is encapsulated in polymer gel results in the 
formation of complex structure comprising of particles of various dimensions embedded into polymer gel surrounded the polycrystalline phase of nanofillers.

\section{Conclusions}

Polymer-based $\mathrm{ZnO} / \mathrm{TiO}_{2}$ NCs flexible sheets with high dielectric permittivity and low loss factor have numerous applications in light emitting and energy storage devices. In this work, polymer-based $\mathrm{ZnO} / \mathrm{TiO}_{2} \mathrm{NCs}$ are synthesized by co-precipitation technique. The development of various diffraction planes (X-rays diffraction analysis) related to $\mathrm{TiO}_{2}$ and $\mathrm{ZnO}$ phases confirms the synthesis of polycrystalline polymer-based $\mathrm{ZnO} / \mathrm{TiO}_{2}$ NCs. The crystallinity of various phases is associated with increasing $\mathrm{ZnO}$ nanofillers. The surface morphology (scanning electron microscopic analysis) comprising of nanoparticles of different shapes is associated with increasing amount of nanofillers. The EDX analysis confirms the presence of $\mathrm{Zn}, \mathrm{O}$ and $\mathrm{Ti}$ in the synthesized polymer-based $\mathrm{ZnO} / \mathrm{TiO}_{2}$ NCs. Dielectric measurements demonstrating the sharp increase in dielectric permittivity with relatively low dissipation factor of synthesized polymerbased $\mathrm{ZnO} / \mathrm{TiO}_{2} \mathrm{NCs}$ are associated with increasing amount of $\mathrm{ZnO}$ nanofillers. The static value of dielectric constant $\left(\varepsilon^{\prime}\right)$ at low frequency $(100 \mathrm{~Hz})$ is found to be 14.56 for sample having $10 \%$ $\mathrm{ZnO}$ nanofillers that is 2.11 times greater than pure PVDF and it shows relatively low value of dissipation factor. The observed $\sigma_{\mathrm{ac}}$ of synthesized polymer-based $\mathrm{ZnO} / \mathrm{TiO}_{2} \mathrm{NCs}$ at $3.0 \times 10^{5} \mathrm{~Hz}$ and $1.0 \times 10^{6} \mathrm{~Hz}$ are ranged from $3.75-9.79$ and $15.61-42.72 \mu \mathrm{S} / \mathrm{m}$ respectively. The decreasing complex impedance and increasing electric modulus further confirm that the synthesized polymer-based $\mathrm{ZnO} / \mathrm{TiO}_{2} \mathrm{NCs}$ flexible sheets are the promising candidate for better capacitive performance showing high strength and flexibility.

\section{Acknowledgements}

This research work is self-supported because the flexible sheets of polymer-based $\mathrm{ZnO} / \mathrm{TiO}{ }_{2}$ NCs are synthesized in authors Laboratory without funding. One of the authors (N. Kanwal) is grateful to Dr. Murtaza Saleem and Dr. Adnan Ali for LC, SEM, EDX and XRD analysis. 


\section{References.}

[1] L.L. Beecroft, C.K. Ober, Nanocomposite materials for optical applications. Chem. Mater. 9, 1302-1317 (1997)

[2] R.V. Kumar, R. Elgamiel, Y. Diamant, A. Gedanken, Sonochemical preparation and characterization of nanocrystalline copper oxide embedded in (polyvinyl alcohol) and its effect on crystal growth of copper oxide. Langmuir 17, 1406-1410 (2001)

[3] D.R. Denison, J.C. Barbour, J.H. Burkart, J. Vac, Low dielectric constant, fluorine doped $\mathrm{SiO}_{2}$ for intermetal dielectric. Sci. Technol. 14, 1124 (1996)

[4] M. Tada, Y. Harada, K. Hijioka, H. Ohtake, T. Takeuchi, S. Saito, T. Onodera, M. Hiroi, N. Furutake, Y. Hayashi, $\mathrm{Cu}$ Dual damascene interconnects in porous organosilica film with organic hard-mask and etch-stop layers for $70 \mathrm{~nm}$-node ULSIs, IEEE Int. Interconnect Technol. Conf. 12-14 (2002)

[5] S.H. Rashmi, A. Raizada, G.M. Madhu, A.A. Kittur, R. Suresh, H.K. Sudhina, Influence of zinc oxide nanoparticles on structural and electrical properties of polyvinyl alcohol films. Plast. Rubber Compos. 44, 33-39 (2015)

[6] S. Mallick, Z.Ahmad, F. Touati, R. A. Shakoor, Improvement of humidity sensing properties of $\mathrm{PVDF}^{-\mathrm{TiO}_{2}}$ nanocomposite films using acetone etching. Sensors and Actuators B: Chemical 288, 408-413 (2019)

[7] S.Ishaq, F. Kanwal, S.Atiq, M.Moussa, U. Azhar, I. Gul, D.Losic, Dielectric and impedance spectroscopic studies of three phase graphene/titania/poly (vinyl alcohol) nanocomposite films. Results in Physics 11, 540-548 (2018)

[8] S.Sugumaran, C. S. Bellan, Transparent nano composite $\mathrm{PVA}^{-\mathrm{TiO}_{2}}$ and $\mathrm{PMMA}^{-\mathrm{TiO}_{2}}$ thin films: Optical and dielectric properties. Optik, 125 (18), 5128-513 (2014)

[9] A.Mills, G.Hill, S.Bhopal, I. P. Parkin, S. A. O Neill, Thick titanium dioxide films for semiconductor photocatalysis. Journal of Photochemistry and Photobiology A: Chemistry 160 (3), 185-194 (2003)

[10] K.Keis, C. Bauer, G.Boschloo, A. Hagfeldt, K.Westermark, H. Rensmo, H.Siegbahn,. Nanostructured $\mathrm{ZnO}$ electrodes for dye-sensitized solar cell applications. Journal of Photochemistry and photobiology A: Chemistry 148 (1-3), 57-64 (2002) 
[11] P.K.C.Pillai, G.K. Narula, A.K. Tripathi, Dielectricproperties ofindustrial polymercomposite materials. Polym. J. 16, 575 (1984)

[12] I. A. Khan, N.Amna, N. Kanwal , M.Razzaq, A.Farid, N.Amin, R.Ahmad, Role of oxygen pressure on the structural, morphological and optical properties of $\mathrm{c}-\mathrm{Al}_{2} \mathrm{O}_{3}$ films deposited by thermal evaporator. Materials Research Express 4 (3), 036402 (2017)

[13] S.Pervaiz, I. A.Khan, S. A. Hussain, N. Kanwal, A.Farid, M.Saleem, Polymer Based ZnO-

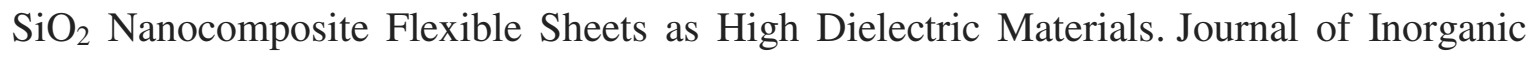
and Organometallic Polymers and Materials 31(1), 209-219 (2021)

[14] I.Ghafoor, S. A.Siddiqi, S. Atiq, S. Riaz, S.Naseem, Sol-gel synthesis and investigation of structural, electrical and magnetic properties of $\mathrm{Pb}$ doped $\mathrm{La}_{0.1} \mathrm{Bi}_{0.9} \mathrm{FeO}_{3}$ multiferroics. Journal of Sol-Gel Science and Technology 74(2), 352-356 (2015)

[15] N.Wang, J. Cheng, A. Pyatakov, A. K. Zvezdin, J. F. Li, L. E.Cross, D. Viehland, Multiferroic properties of modified $\mathrm{Bi} \mathrm{FeO}_{3}-\mathrm{PbTiO}_{3}$-based ceramics: Random-field induced release of latent magnetization and polarization. Physical Review B 72(10), 104434 (2005)

[16] I.Tantis, G.C.Psarras, D.Tasis, Functionalized graphene--poly (vinyl alcohol) nanocomposites: Physical and dielectric properties. Express Polymer Letters. 6 (4) (2012)

[17] A.Kalini, K. G.Gatos, P. K.Karahaliou, S. N. Georga, C. A. Krontiras, G.C.Psarras, Probing the dielectric response of polyurethane/alumina nanocomposites. Journal of Polymer Science Part B: Polymer Physics 48 (22), 2346-2354 (2010)

[18] C.S.Lakshmi,C.S.Sridhar,G.Govindraj,S.Bangarraju, D. M. Potukuchi,Structural, magnetic and dielectric investigations in antimony doped nano-phased nickel-zinc ferrites. Physica B: Condensed Matter 459, 97-104 (2015)

[19] K.Prabakar, S. K.Narayandass, D.Mangalaraj, Dielectric properties of $\mathrm{Cd}_{0.6} \mathrm{Zn}_{0.4} \mathrm{Te}$ thin films. physica status solidi .199 (3), 507-514 (2003)

[20] S.Nasir,G.Asghar, M. A. Malik, M. Anis-ur-Rehman,Structural, dielectric and electrical properties of zinc doped nickel nanoferrites prepared by simplified sol-gel method. Journal of sol-gel science and technology 59(1), 111-116 (2011)

[21] A.K.Dubey, P. Singh, S. Singh, D. Kumar, O.Parkash, Charge compensation, electrical and dielectric behavior of lanthanum doped $\mathrm{CaCu}_{3} \mathrm{Ti}_{4} \mathrm{O}_{12}$. Journal of alloys and compounds 509(9), 3899-3906 (2011) 
[22] M.Amin, H. M. Rafique,M.Yousaf, S. M. Ramay,S.Atiq, Structural and impedance spectroscopic analysis of $\mathrm{Sr} / \mathrm{Mn}$ modified $\mathrm{BiFeO}_{3}$ multiferroics. Journal of Materials Science: Materials in Electronics 27(10), 11003-11011 (2016)

[23] F.Yakuphanoglu,Electrical conductivity and electrical modulus properties of $\alpha, \omega$ dihexylsexithiophene organic semiconductor. PhysicaB: Condensed Matter 393(1-2),139142 (2007)

[24] A.TATAROĞLU,Frequency and voltage dependence of the electrical and dielectric properties of $\mathrm{Au} / \mathrm{n}-\mathrm{Si}$ Schottky diodes with $\mathrm{SiO}_{2}$ insulator layer. Journal of Optoelectronics and Advanced Materials 13, 940-945 (2011)

[25] A. A. M.Farag, A. M Mansour, A. H.Ammar, M. A.Rafea, A. M. Farid,Electrical conductivity, dielectric properties and optical absorption of organic based nanocrystalline sodium copper chlorophyllin for photodiode application. Journal of alloys and compounds. 513, 404-413 (2012)

[26] K.P.Singh, P.N.Gupta,Study of dielectric relaxation in polymer electrolytes. European Polymer Journal. 34(7), 1023-1029 (1998)

[27] T.Z.Rizvi, A.Shakoor Electrical conductivity and dielectric properties of polypyrrole/Na+montmorillonite (PPy/Na+-MMT) clay nanocomposites. Journal of Physics D: Applied Physics. 42(9), 095415 (2009)

[28] S.Atiq,M.Majeed,A.Ahmad, S.K.Abbas, M., Saleem, Riaz, S., \& Naseem, S. Synthesis and investigation of structural, morphological, magnetic, dielectric and impedance spectroscopic characteristics of $\mathrm{Ni}-\mathrm{Zn}$ ferrite nanoparticles. Ceramics International. 43(2), 2486-2494 (2017)

[29] K.M.Batoo, M. S. Ansari,Low temperature-fired Ni-Cu-Zn ferrite nanoparticles through auto-combustion method for multilayer chip inductor applications. Nanoscale research letters 7(1), 1-14 (2012)

[30] H.Singh, A.Kumar, K. L Yadav,Structural, dielectric, magnetic, magnetodielectric and impedance spectroscopic studies of multiferroic $\mathrm{BiFeO}_{3}-\mathrm{BaTiO}_{3}$ ceramics. Materials Science and Engineering: B. 176 (7), 540-547 (2011)

[31] M. A.Dar, V.Verma,S. P.Gairola, W.A.Siddiqui, R. K.Singh,R. K. Kotnala, Low dielectric loss of $\mathrm{Mg}$ doped $\mathrm{Ni}-\mathrm{Cu}-\mathrm{Zn}$ nano-ferrites for power applications. Applied Surface Science 258(14), 5342-5347 (2012) 
[32] S.Pattanayak, B. N.Parida,P.R Das, R. N. P. Choudhary,Impedance spectroscopy of Gddoped $\mathrm{BiFeO}_{3}$ multiferroics. Applied Physics A. 112 (2), 387-395 (2013)

[33] D. K. Pradhan, B. K.Samantaray, R. N. P.Choudhary, A.K.Thakur, Complex impedance analysis of layered perovskite structure electroceramics-NaDyTiO.Journal of materials science 40(20), 5419-5425 (2005)

[34] G.Singh, V. S. Tiwari,Effect of Zr concentration on conductivity behavior of (1-x) PMNxPZ ceramic: An impedance spectroscopy analysis. Journal of Applied Physics 106(12), 124104 (2009)

[35] G.C.Psarras, E.Manolakaki,G.M.Tsangaris, Dielectric dispersion and ac conductivity inIron particles loaded-polymer composites. Composites Part A: Applied Science and Manufacturing 34(12), 1187-1198 (2003)

[36] P.Dutta,S.,Biswas,S.K.De, Dielectric relaxation in polyaniline-polyvinyl alcohol composites. Materials Research Bulletin 37(1), 193-200 (2002)

[37] M.D.Migahed, M.Ishra,T.Fahmy,A.Barakat, Electric modulus and AC conductivity studies in conducting PPy composite films at low temperature. Journal of Physics and Chemistry of Solids 65(6), 1121-1125 (2004) 